\title{
Addressing Radicalisation into the Classroom - A New Approach to Teacher and Pupil Learning
}

\author{
Dr Jane Reeves \\ Co-Director Centre for Child Protection, University of Kent \\ Giles Lane, Canterbury, Kent, CT2 7LR, UK \\ Tel: 01227278687 Email: J.Reeves@kent.ac.uk
}

\author{
Alamgir Sheriyar (Corresponding author) \\ Active Referral Co-ordinator Kent Police \\ Tel: 07807340239 Email: alamgir.sheriyar@kent.pnn.police.uk
}

$\begin{array}{lr}\text { Received: January 30, } 2015 & \text { Accepted: February 10, } 2015 \quad \text { Published: February xxxx, } 2015 \\ \text { doi:10.5296/jet.v2i2.7129 } & \text { URL: http://dx.doi.org/10.5296/jet.v2i2.7129 }\end{array}$

\begin{abstract}
This article examines one response to the UK Government's directive that radicalisation and extremism should be tackled in all UK secondary schools. The small scale study is set in the broader literature of teaching often difficult Personal, Social and Health Education (PSHE) topics to young people in secondary school, and also the use of simulations as tools for learning in the classroom. It analyses the responses of teachers to being trained with, and using, 'Zak' a bespoke research-based simulation on the radicalisation process. An analysis of the teachers' responses indicated recognition that the principles of adults manipulating children, whether for sexual gratification or radicalisation, are considered to be very important topics for staff working with young people in school settings to address. It was also recognised as a flexible learning tool enabling various pathways to be explored with young people in lessons, addressing the many aspects of e-safety, not just radicalisation. Additionally, the teachers remarked that the social media 'Facebook' format of the simulation was appreciated by the young people, and this appeal resulted in their immersion with it as a teaching aid. The comprehensive delivery of the 'Zak' package into schools was also significant. Staff reported that the inter-professional training delivered by specialist police trainers, and the accompanying materials, enhanced the learning and confidence of the teachers on this multi-faceted and complex topic.
\end{abstract}

Keywords: Radicalisation and Extremism; Teaching and Learning; Simulations; PSHE 


\section{Context of Radicalisation in UK Schools}

In the UK, the "School Inspection Handbook" (2014) states, in terms of the behaviour and safety of pupils at the school, that Ofsted inspectors should now consider:

"the extent to which pupils are able to understand, respond to and calculate risk effectively, for example risks associated with child sexual exploitation, domestic violence, female genital mutilation, forced marriage and substance misuse, gang activity, radicalisation and extremism and are aware of the support available to them." (2014:54).

There has been a high profile focus on child sexual exploitation (CSE) in the UK, especially with the campaigns and materials and products produced by CEOP. The Personal Social and Health Education (PSHE) programme addresses a range of topics and can include teenage pregnancy; domestic violence; forced marriage; sexual health; friendship; gang activity and radicalisation. Variable resources are available to support teachers, who are probably not experts in any of these topic areas. Indeed, how pupils are taught about these complex and difficult topics and the methods used to do so are the subject of much debate - do schools bring in one-off 'experts' to tackle an issue which could be a year-long issue for some pupils or do schools send staff off for bespoke, if costly, Continuing Professional Development (CPD)? In one study teachers express how inadequately trained they feel for dealing with many of the areas covered in the PSHE programme:

"Many teachers however lack confidence and feel underprepared in tackling controversial global issues, in terms both of knowledge and methods. They fear children would be anxious if war were discussed, that ethnic tensions in the class would be heightened, or that they should not present their own views." (Davies et al., 2005:4)

In terms of radicalisation and extremism in the UK, as a topic to be addressed, 2014 is the first time it has become part of the Ofsted inspection assessment,with radicalisation and extremism becoming an increased focus for concern by the government (Government Task Force: Cabinet Office, 2013). In schools, for example in Birmingham (http://www.bbc.co.uk/ news/education-27024881) and also having high profile reporting in the media (www.parliament.uk/business/committees/radicalisationinschools) the focus is on how schools are dealing with these topics.

The PREVENT strategy in the UK was launched in 2007 and sought to address terrorism. It was the preventative strand of the government's counter-terrorism strategy, CONTEST. In 2011 the agenda was re-launched by the Coalition Government.

The Prevent agenda sought to:

- respond to the ideological challenge of terrorism and aspects of extremism, and the threat we face from those who promote these views

- provide practical help to prevent people from being drawn into terrorism and ensure they are given appropriate advice and support 
- $\quad$ work with wide range of sectors where there are risks of radicalisation which we need to address, including education, criminal justice, faith, charities, the internet and health ${ }^{1}$

As part of the strategy to deliver this, police and partners in the local authority and University consulted to work together as part of this PREVENT programme.

The University was initially approached because the Centre for Child Protection (CCP) was pioneering the use of simulations and 'serious games' for child protection training, both with professionals and young people. The Centre has now developed a portfolio of 'serious game' simulations on key aspects of child protection. They tackle complex inter-professional issues including sexual abuse ('Rosie 1' - which can be downloaded free from the Centre for Child Protection Website ${ }^{2}$ ); neglect ('Rosie 2' collaboration with Health); extremism and online grooming ('Zak' in collaboration with the police); assessing risks for sexual offenders ('Visiting Elliot' in collaboration with the police and probation); and child sexual exploitation ('Looking out for Lottie' in collaboration with the National Health Service Kent, Surrey and Sussex). These simulations transform research findings into useable and interactive resources tackling difficult practice issues. Products of collaborative working with local and national agencies, they provide tools of excellence for multi-agency practice. 'Zak' was developed to be a tool for use in the classroom, for young people to address issues from the Prevent strategy, to explore the complexities surrounding the topics of radicalisation and online grooming. Its development was based upon research on the causations of radicalisation (set out in table 1). The case used for the scenario was developed using a combination of live and previous cases, for example Umar Farouq Abdulmutallab, a former student in London, who was radicalised under the influence of Anwar Alwalaki; and Abdulla Ahmed Ali, who was convicted for the liquid bomb plot, who was also student in London until 2002Table 1.

- Faith/Ideology Issues (Hoffman, 2006)

- Social Mobility (Al-Lami, 2009)

- Physical/Mental health issues

- Risk/Harm Factors

- Criminal Activity (Hacker, 1976)

- Justice (Bartlett, Birdwell, \& King, 2010)

- Threats

- Identity/belonging (Borum, 2004)

- Excitement /Adventure (Silke, 2008)

- Status

- Dominate/Indoctrination

- Political/ moral motivation (Speckhart, 2007)

- Opportunist involvement

- Family friend supporting extremism (Razzaque, 2008)

- Transitional period (Silke, 2008)

- Group influence
Factors associated with radicalisation.

It appears that social media is now an important tool in the radicalisation and recruitment of people who become involved in political violence and this relates to the assessment of e-safety in the Ofsted criteria now. Research from the

\footnotetext{
1 http://www.homeoffice.gov.uk/counter-terrorism/review-of-prevent-strategy/

2 www.kent.ac.uk/sspssr/ccp
} 
International Centre for the Study of Radicalisation and Political Violence (ICSR) (December 2013) estimated that 1,900 people from Western Europe had travelled to Syria to fight - 366 of these were from the United Kingdom. The Director of ICSR, Professor Neumann has stated

"One thing we had done in the past was to take an interest in what we can learn from the presence of extremists on social media. What we discovered was that the foreign fighters who started to join the insurgency in 2012 were all on social media....." (Laville, S. Guardian Newpaper $15^{\text {th }}$ April 2014)

The ICSR has linked extremist groups with the movement to Syria of young British men and some young British women from around the UK recent publicity cites the cases of Abdul Waheed Majeed aged 41, from Crawley who drove a van with explosives into a prison in Aleppa, Syria after joining an aid convoy to Syria. Other examples are Iftikhar Jaman, aged 23, who died in December 2013, and is acknowledged by ICSR as having a 'humanitarian motivation to fight Jihad in order to help the Syrian people'. Neumann states "There will be a minority of people coming back who are brutalised and radicalised and have acquired very good terrorist skills who can produce explosive devices and who know how to handle weapons. It is proposed that this minority of people could become engaged in terrorist offences on their return to the UK." The Guardian estimates (14th April 2014) that in the first quarter of 2014 there have been about 30 arrests in the UK related to terrorist offences by individuals attempting to travel to Syria or on their return. A recently publicised case is 18 year old Abdullah Deghayes from Brighton, who died in Syria in April 2014, his father discovered the news on Facebook.

The findings by ICSR (2014 p.1) outline that social media represents an essential source of information and inspiration to potential western recruits and that social media is no longer seen by them as virtual but as 'an essential facet of what is happening on the ground'. Information about conflict (in Syria) is often not received through official channels but via sympathisers - so-called 'disseminators' all through internet social media sources.

One of the overarching aims of Zak is to raise awareness of the potential links between social media and radicalisation for young people, so that they can explore, $i$ in the safe facilitated environment of school, the possible signs and circumstances of this type of grooming.

\subsection{Zak as Teaching Aid}

The Zak programme emulates a social media site with photos, chat, likes and shares. It aims to provide teachers and educators with an innovative focus in the classroom that will facilitate discussion on the topics of extremism, radicalisation and internet safety. These are complex subjects which teachers in this area may know little about and in recognition of this Zak was developed with a training pack with classroom activities and short videos aimed at different age groups as well as regular training days for teachers and allied health and social care professionals. The police and University hosted these regular half-day training opportunities throughout 2013/2014 to explain the context and potential uses for Zak and provide advice, 
guidance and training to maximise the use of the resource. The training highlights the background to Zak, how the resources can be used to full effect in the classroom and also to ensure that staff are aware of safeguarding procedures and where to signpost young people in instances where issues are raised.

Zak meets the learning outcomes for PSHE or Citizenship, as well as other education criteria for key skills, such as: communication, information and communication technology, working with others, improving own learning and performance, and problem solving. Zak also aptly meets the safeguarding agenda and meets e-safety requirements set by Ofsted as follows:

"Provide an age-related, comprehensive curriculum for e-safety that enables pupils to become safe and responsible users of new technologies."

"Work with their partners and other providers to ensure that pupils who receive part of their education away from school are e-safe." (Ofsted 2014 Inspecting e-safety p5)

Features of good and outstanding practice are measured by the following criteria:

"All teaching and non-teaching staff can recognise and are aware of e-safety issues."

"High quality leadership and management make e-safety a priority across all areas of the school (the school may also have achieved a recognised standard, for example the e-Safety Mark)."

"A high priority given to training in e-safety, extending expertise widely and building internal capacity."

\subsection{Using Simulation in Learning With Young People}

Education technologies which are online and interactive have been highly effective with young people (De Frietas \& Maharg 2011). Debates surround the escalation of young people's digital social connections and how adept they are at gaming, which are now a part of young people's lives and how they 'play' in their teenage years.

"Thanks to instant messaging, online chat rooms, multiplayer gaming, and the like-all forms of 'social networking' that permit young people to have private, real time conversations with people across the world" (Brennan 2011:17).

The current generation is unique in how it uses, becomes immersed in and understands contemporary technology. Young people learn in different ways, visually, auditory and kinaesthetically; moreover, many learners are now 'digital natives' \& have 'exceptional visual literacy skills' and can cope with 'multiple streams of information' (Bellotti et al., 2011).

Making the transition to the classroom with simulations can be controversial, particularly for teachers, some of who can feel intimidated by their lack of skills and understanding in contrast to their pupils (Brennan, 2011; Oserweil \& Kopfer, 2011). In purely practicable terms 'the mere 
process of implementing computer based learning activities typically required dealing with the 'computer room' in the school' (Oserweil \& Kopfer, 2011:158). This often oversubscribed room is often not conducive for peer discussion (a key feature of Zak) or teacher interaction and management of this, and the technical aspects of 'getting a game to work' in this environment can put teachers and facilitators off. Additionally, some gaming tools for use with young people often require a degree of computer sophistication and knowledge which can make teachers feel uncomfortable and necessitate further training.

However, games and simulations are effective for stimulating discussion. One of the key elements identified in drawing in young people to the use of games and learning is the narrative of the story, as well as the emotion and arousal the characters provoke. In response to this it has been highlighted that several key features should be incorporated into any learning game, namely, clearly signposting the key educational themes that are to be covered; the game should allow young people to explore their own identities; the simulation or tool should not patronise or flatter and they do not have to be gendered (Oserweil \& Kopfer 2011). We strove to incorporate all of these elements into Zak and the gameplay illustrates this.

However, by far the most important element of Zak is as a tool for stimulating debate with young people, enabling teachers need to understand the development of children and young people's values and moral reasoning in the age of digital technology and social media (Brennan 2011). Brennan argues;

"Teachers need to form an understanding of the development of children's moral reasoning in the information age. It is through interaction with others that young people develop their framework for reasoning about moral issues and, as established by Piaget and Kohlberg, these interactions are shaped by the child's level of cognitive development. In the case of teenagers and young people communicating online this is an environment where there is little effective feedback from the other person. With fewer or no visual signs and a physical distance between the young person and the consequences of their actions, there is less chance they will develop a clear understanding of the cause and effect relationship. It is therefore important that teachers become familiar with the online environment, where online social conventions may be different to the real world. In this way the levels of internalised empathy will be raised and respect, moral reasoning and self-control will be developed so the young people's actions are guided internally. This will allow them to participate and thrive in an environment that seemingly allows or even encourages the disengagement of moral control." (2011: 19)

In a study by See and Arthur (2011) secondary school pupils implied 'that formal education has not done much to develop their character' rather that their values were 'shaped by their school experiences outside the curriculum'. See and Arthur (2011) remark that 'this is in some contrast to the views of teachers who report formal activities intended to promote character development. While teachers advocate the need to be good role models, pupils do not always see such qualities in their teachers. Teachers need to reflect in their behaviour, the kind of behaviour they want to see in their pupils and in society'. (2011:143)

It appears a difficult road to navigate as one secondary school head remarked 


\section{Ml Macrothink}

Journal of Education and Training

ISSN 2330-9709

2015, Vol. 2, No. 2

There is a limit to how controversial you can be in schools and how political but these are very important issues and kids are entitled to explore them.

Zak is important because it allows teachers and young people to inhabit the same online space and gameplay, sharing the same rules and conventions. By sharing this teachers can explore the young person's understanding of what is and is not acceptable in terms of behaviour and how they act, but also of how they should protect themselves. Zak is about being groomed, manipulated, making moral choices and ultimately being pressured to act illegally; young people need platforms to interpret and provide moral guidelines in the contemporary world. Thompson and Holland (2002) in their study of the negotiation of moral authority and understanding of the value systems of young people, point to the considerable complexities young people have to work through in contemporary late modern society:

"The young people grapple with multiple and diverse moral frameworks emanating from both near at hand (the school, the family, the peer group, religious affiliation, local setting) and more generally (media mediated global youth and other cultures) with increasing moral dexterity" (Thompson and Holland 2002:114)

They identify that one key agent stood out for the young people as a figure through which they organised their values and ethical dilemmas; the teacher.

“The figure of the 'teacher' stands at the centre of moral discourse. The way in which young people engage with this figure differs dramatically between the more public aspects of school life and the more private aspects of home life." (Thompson and Holland 2002:115)

Thus by facilitating such composite issues as radicalisation and extremism which combine morality, ethics, values, class, gender, religion and beliefs and asking teachers to bring about and mitigate the discussion, teachers are both the agents of debate and moral mentors for these potentially tricky discussions. In this context, 'Zak' was designed with 6 key learning objectives

- Increase the awareness of young people around the process of radicalisation of individuals, particularly those who are involved in the transition from home to University.

- Enable young people to identify and discuss factors/indicators of radicalisation in their peers.

- Encourage young people to consider aspects of internet safety

- Encourage self-reflection on their own \& others behaviour.

- Facilitate understanding regarding where and to whom young people should report their concerns on radicalisation and internet safety

- Identify some of the procedures in place to support individuals in a pre-criminal space. 


\section{Macrothink}

\subsection{Modes of learning for Zak}

Zak is designed to be played by a whole class, split into peer groups of 3 or 4 around a computer and run by a facilitator on an interactive whiteboard. Everything in the simulation is clickable, revealing greater depth. By clicking on an event in the timeline, the class will be able to grade it - as a sign of influence, as a sign of evidence, or as a red herring that is totally unrelated to radicalisation. As a non-linear game, the use of this content can be tailored to both short and long classroom sessions and to different age groups - year $9 / 10$ or years $12 / 13$. The traffic-light scoring mechanism grades the evidence collected. By prompting a reappraisal of the evidence instead of spoon-feeding 'right' or 'wrong' answers, the educational value from the game is reinforced. Ideally, the students need to have a lesson on key elements and words associated with radicalisation the week prior to using Zak and the lesson needs to end with a de-brief of some of the key or critical moments in the game - i.e. why it was significant and what could have been done at this point (See appendix for Table 2).

At the end of the timeline, there are two videos. Zak speaks to the young people about where his life went from this point. One highlights the importance of positive interventions and the return of support structures whilst the other shows what can happen if those interventions and support mechanisms are not put in place. Students are asked to comment on the consequences of each ending for Zak and the wider community.
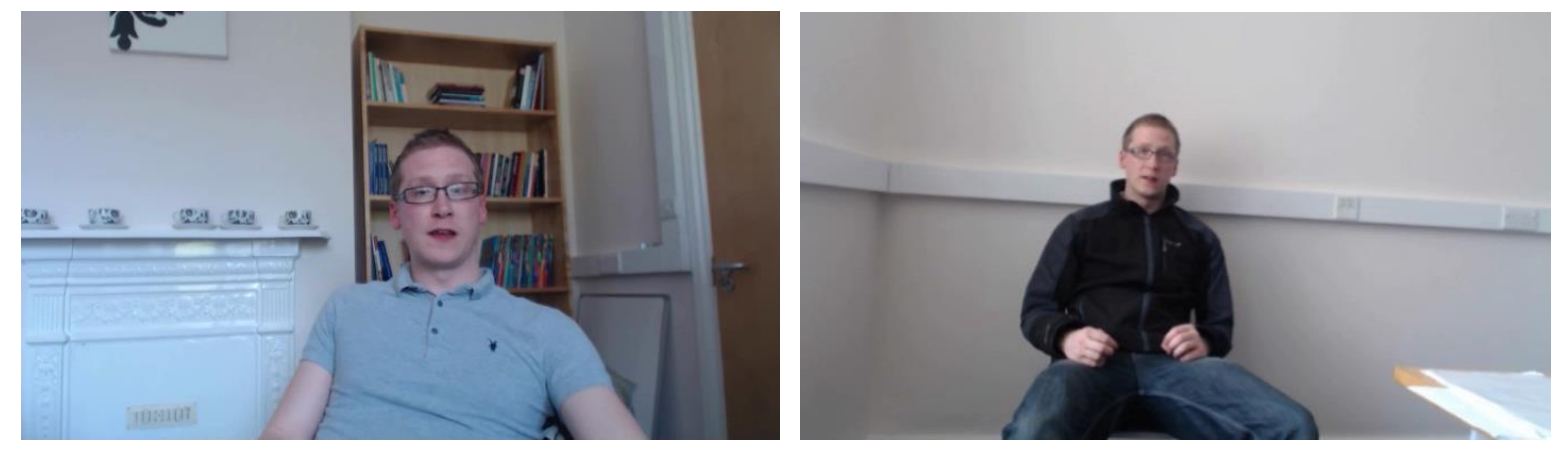

\section{Research design}

This evaluation is based upon a pilot of Zak, open to all Kent secondary schools and Kent organisations that had received training and were using Zak during the period September 2013 to March 2014.

\subsection{Method}

A research assistant was employed from January - April 2014 to review the feedback that was gathered through questionnaires, designed by CCP. The questionnaire was available electronically but was also administered in some instances by police specialist trainers following teaching and learning sessions. The questionnaire requested demographic information and asked teaching staff to evaluate their responses to the police-led Zak training, to share their views about Zak as a teaching aid and also to comment, where appropriate, on 
their students' responses to Zak.

The evaluator also conducted small focus group meetings and collated e-mail feedback in addition to the questionnaire returns as further sources of evidence for the evaluation. Since postal questionnaires as a method of survey have a notoriously low return rate electronic availability improved the rate of return ( Nulty 2008; Brace 2013). The follow up focus group interviews were initiated, to provide qualitative evidence to triangulate the quantitative findings of the questionnaires.

Fourteen members of school staff returned completed questionnaires. Additionally three members of staff from secondary schools gave interviews regarding their use of Zak. Six parents of secondary school aged children also completed questionnaires. Furthermore, written feedback was obtained, following training in June 2013, from forty six participants from a wide range of multi-agency settings in health, education, youth offending and social care regarding the Zak simulation training day. Expressions of interest from participants who had undertaken the training days indicated that Zak had potential application at junior school level. To pursue the potential viability of this feedback the evaluator undertook an additional small sample survey whereby seven members of staff from three junior schools contributed their perspective on the viability that Zak could potentially engage a younger cohort of children from primary school age. This was undertaken by two one-to-one interviews and one focus group discussion.

Ethical permission had been granted by the University ethics committee to survey and interview adult respondents over the age of eighteen. Teachers and other professionals who used Zak reported, where appropriate, via the questionnaire, the responses of their students to the simulation as ethical permission was not sought for this initial pilot to research the views and opinions of minors. Therefore, young people under the age of eighteen were not approached and did not provide direct feedback for this stage, however, it is anticipated that this will be a focus for a further study

\section{Results and discussion}

\subsection{Demographic Information}

Zak is hosted by the University on its platform 'Moodle' to which all schools who used Zak were given login details. During the period from June 2013 until March 2014 the University recorded 1,154 logins to Zak on their Moodle site, indicating a high rate of traffic by professionals trying out the simulation.

The demographic information of respondents who used Zak with student groups and returned questionnaires are detailed in this section. The respondents were based in schools from varying locations in the county, and from a range of schools, including Grammar Schools and High Schools.

A variety of staff used Zak with young people in the classroom and the data are illustrated in Figure 1, with the majority being teachers. 


\section{Types of staff (position) using Zak in the classroom $(\mathrm{N}=14)$}

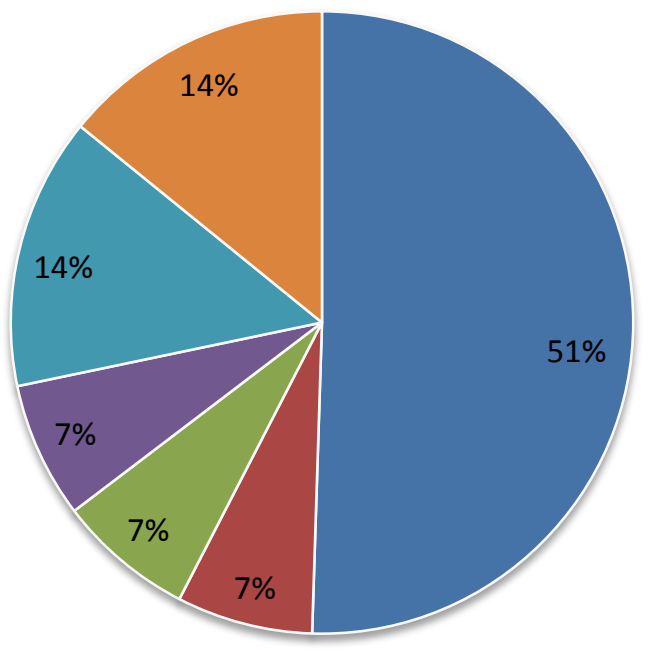

- Teacher

- Teaching Assistant

- Assistant Head Teacher

- 6th Form Manager

- Cover Supervisor

Other

Figure 1. Types of staff using Zak in the classroom

Moreover, Zak was used with a variety of year groups; Figure 2 illustrates this.

\section{Distribution of year groups using Zak $(\mathrm{N}=14)$}

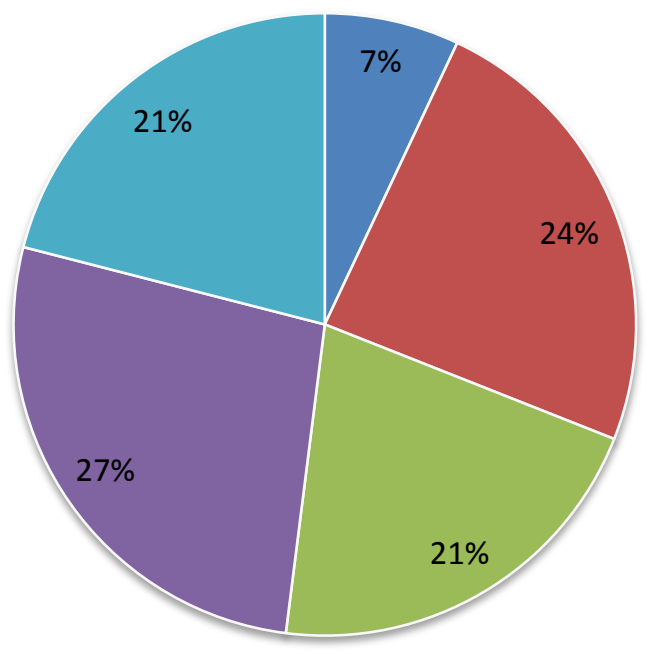

Year 7

- Year 10

- Year 11

- Year 12

Year 13

Figure 2. Distribution of year groups using Zak

The year group that used Zak the most was year 12 (ages 16-17). Zak was used in a variety of ways, including some small group work in a computer suite with the young people 
controlling the game and also being led from the front by a facilitator to much larger groups in a classroom.

\subsection{The Product, Students and Sessions}

Key messages from respondents indicated that the following factors drew them to using Zak including a number of ' 'Facebook' related issues in schools'; 'Social networking is used massively in our school and we have had incidents of grooming here'; It was described as a 'hands-on and interactive resource for exploring e safety and then expanding the horizons of students'; the students 'engaged' because of the familiar format; 'it was something that was different and meaningful'; 'for them it is the reality, it is what they use all the time. 'It makes it more meaningful'; 'Students were actually engaged in the lesson for the whole 2 hours and they interacted.' For some young people it was the only time they had had their views challenged; 'We have a lot of young people with very extreme views that are not often challenged by peers or their wider social/family networks'.

Staff indicated that Zak was an easy tool to use with all respondents reporting 'good' or 'excellent'. There were no reports that they were unsure about usage or that they found Zak poor or very poor to use.Disadvantages of using the simulation were reported as being minor, but included some young people 'rushing' through the simulation to get to the end and others, particularly those with ASD, having problems with conceptualising a 'fictional situation'. For some teachers the problems were more practical - wanting to access Zak on Mac computers, which is not compatible with this version of Zak.

One hundred percent of users in secondary schools reported that there were advantages to using a simulation in the classroom in terms of the engagement of the young people. One school found that their network capabilities could not cope with multiple users so they placed students into small groups around one computer. Another school did not have access to a computer room during the session designated for Zak so they printed laminated screen shots. Staff reported that the laminated pack worked very well with their students. The majority of schools, (90\%) found that using Zak generated discussion about radicalisation, not only with young people but also amongst colleagues.

The overwhelming majority of the feedback from secondary schools was positive, commenting on the 'polish' of the product and what a good resource it was to use in the classroom. Respondents reported that students' knowledge about radicalisation, extremism and internet grooming prior to the session on Zak as mostly poor or very poor. Figure 3 indicates the range of responses. 

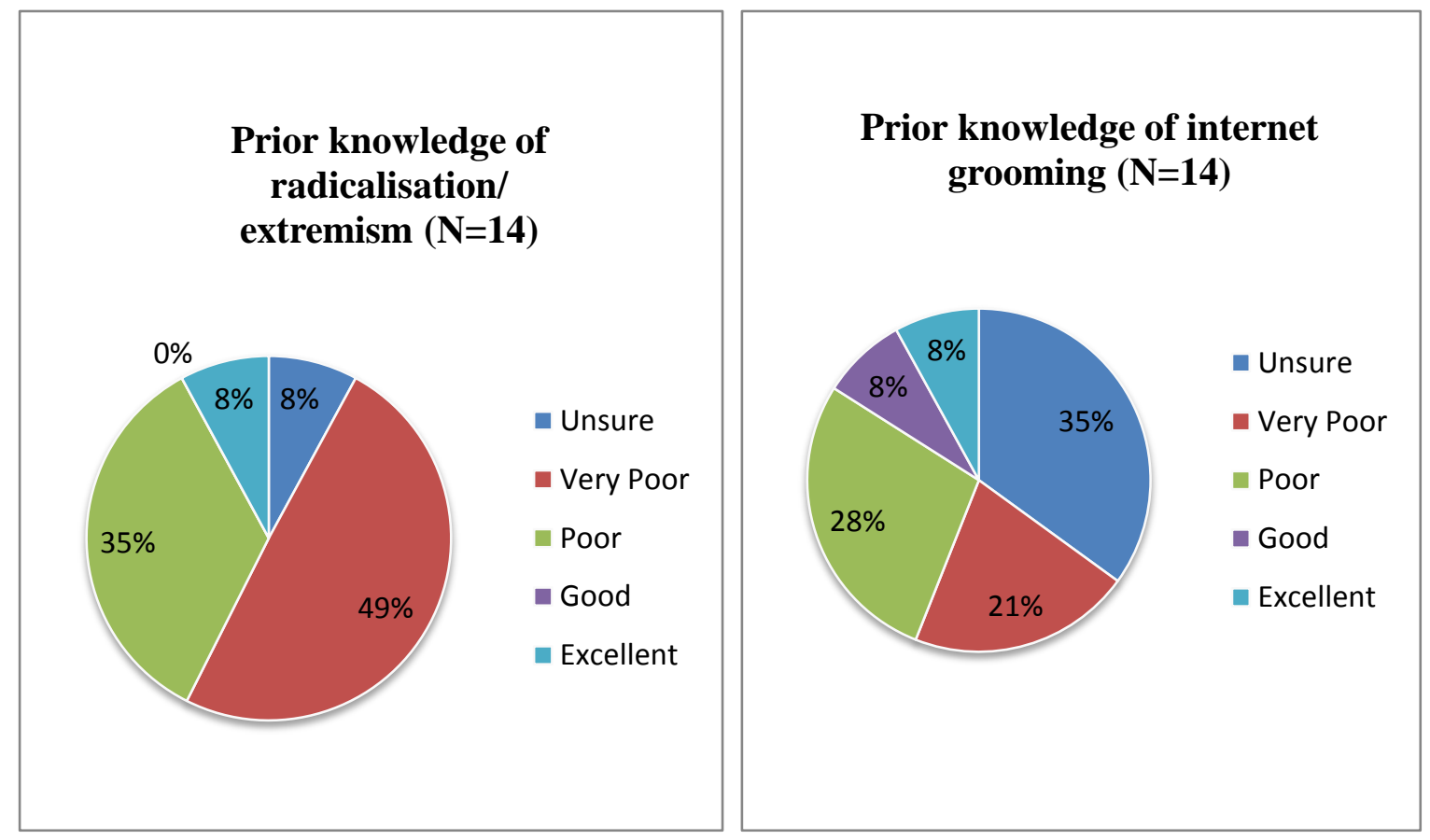

Figure 3. Prior knowledge of grooming and radicalisation

This compares with after the session whereby respondents thought that the student had learned about radicalisation and internet grooming (see figure 4). There were no reports that Zak had not stimulated discussion or that learning had not taken place.

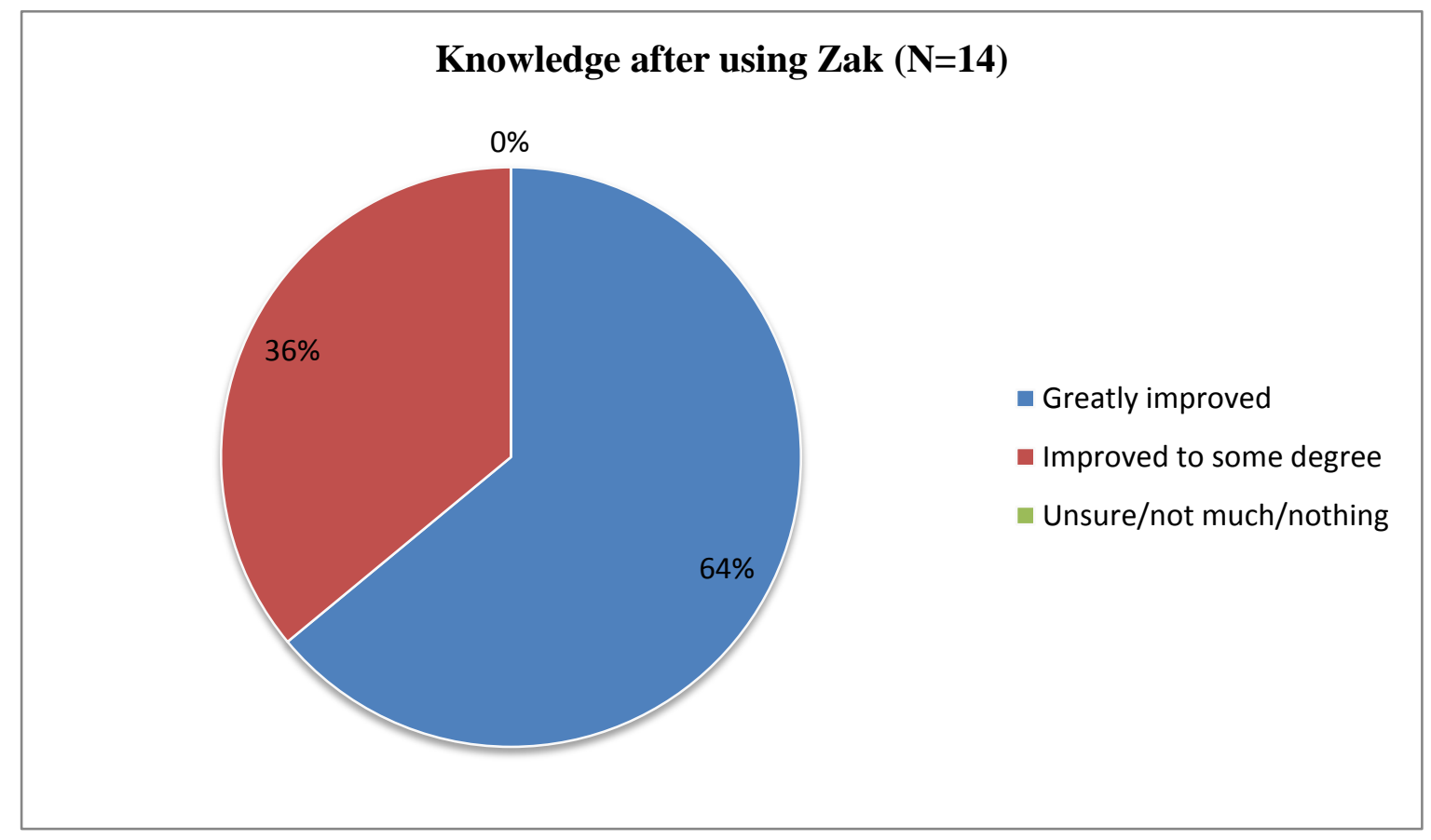

Figure 4. Knowledge of grooming and radicalisation after playing Zak 
When asked if the issues addressed by Zak were a particular problem in their school $71 \%$ of staff (participants) reported that they were. It was reported that extremist/discriminatory/ stereotypical views were expressed by the young people during the session in $29 \%$ of cases. These included a disclosure about a family member, oppressive views and language usage which was homophobic, racist and made derogatory statements which were challenged by staff in various ways, mainly through discussion and question and answer sessions. In $29 \%$ of cases referrals were made to safeguarding channels within school through staff nominated in charge of safeguarding $(n=14)$. On one occasion, during a presentation by the specialist trainer from Kent Police a FE College instigated a referral regarding a vulnerable student to the family liaison officer, via the specialist police trainer.

Respondents reported that students were thoroughly engaged in Zak and in answer to the question 'what went well in the session?' 64\% reported high engagement, 28\% heated discussion and enthusiasm. Twenty one percent of young people particularly enjoyed the visual learning element of Zak; $43 \%$ enjoyed the interactive nature; $50 \%$ particularly enjoyed the social network format with $22 \%$ enjoyed all aspects of Zak $(\mathrm{N}=14)$. No students were reported as expressing dislike or distress regarding the content of Zak and staff felt no content needed changing as potentially causing offence.

The qualitative data revealed slightly more caution as staff interviewed thought that language usage was important in the classroom in terms of using the words 'radicalisation' or 'terrorism' rather than using any reference to the Islamic religion, such as Islamist extremist. This is an important issue that is covered in the training by Kent Police. Staff also expressed that their students felt grooming for radicalisation was 'improbable' in their schools, even though some issues did come out of the sessions.

When asked if they would recommend Zak for use in other schools respondents reported either very highly or highly. Additionally, staff fed back that Zak was '[a] thoughtful, engaging and purposeful resource', describing it as 'an excellent tool that covers a range of topics'. Several respondents thought that conceptually Zak had the potential to work 'within a wide age span'.

As part of the qualitative data collection staff reported to the evaluator that Zak could be used in the following ways

"It would be good as it is for staff training, younger members of staff NQTs. People have lost their jobs because of Facebook." (Primary school staff)

"This would be good for some of our young parents Zak, as it is now. You could get them to talk about racial hatred issues." (Primary school staff)

Respondents reported that the associated training packs were useful with $80 \%$ stating they were excellent and $20 \%$ rating them as good.

\subsection{Respondents'Assessment of Their Own Knowledge}

Respondents' knowledge of radicalisation and extremism prior to the training day was described by $65 \%$ as 'unsure or poor' and only $35 \%$ described their knowledge as 'good'. 


\section{Macrothink}

Participants gave themselves a higher ranking regarding knowledge of internet grooming with $77 \%$ describing their knowledge as 'good' and only $13 \%$ as 'poor or unsure'. Following the training the self-reported confidence levels for staff rose considerably with $70 \%$ describing themselves as confident, $15 \%$ very confident. Fifteen percent described themselves as not confident to deliver Zac to young people in secondary school. $(n=14)$ and consequently partnership working with the police was discussed to help with the delivery.

The questionnaire revealed that $100 \%$ of respondents had received no other training on radicalisation and internet grooming despite it now being part of the Ofsted assessment. The use of Zak as a tool for e-safety was frequently acknowledged in conversation with the evaluator and in comment boxes in the questionnaires. One hundred percent of respondents who attended training planned to use Zak throughout the academic year, 2013/14 and were planning for further use with a variety of year groups for 2014/2015. For 2013/14 respondents stated that they would deliver between 5 and $10+$ sessions, the number of sessions being restricted by the size of their school The sessions that took place in the first two terms of 2013/14 occurred in the following designated subject areas, ranked in order of preference.

1) PSHE

2) Sociology

3) Small group

4) ICT

5) Mentor time

\subsection{The Training by the Police}

The training by the police to teachers was delivered by two officers, one from community education and one from special branch. Participants of the training over the course of the study included practitioners, managers and professionals from health, education, secondary, primary and further education, advocacy and inclusion, social care, to include looked after children, asylum seekers, unaccompanied minors, youth offending, probation, practitioners from community development, a regional parent co-ordinator and a member of staff from the Home Office.

The feedback regarding the training was unanimously positive and it involved active participation and debate. Many participants exalted Zak's use as an e-safety tool and a few participants were very taken with the potential of Zak as a media interactive learning tool and shared their ideas for future development of interactive learning. The following comments illustrate the vibrancy and stimulating enthusiasm the trainers imparted and referred to the importance of the specialist training. 


\section{$\Lambda$ Macrothink}

"The training was excellent and has given more confidence in addressing the issues and teaching in this area. However the nature of our students and their lifestyles made me realise that they need experts in the area to address fully and meaningfully" (Teacher Questionnaire)

"Don't know if you heard but we had OFSTED in....last week. Zak was observed in a sixth form lesson and OFSTED gave feedback that they thought the lesson content was excellent.....Thought you may like to know" (e-mail, received 10/3/2014 school)

"I found the ....session extremely helpful and engaging....We'd love you to come in and do an evening with us" (e-mail, 16/1/2014 youth group)

“...thanks for...hosting a really engaging session with some of our sixth form students. Witnessing the cogs turning and the sparks flying was fantastic to see and I know they took a lot from the session. Having professionals come in from outside the school is immensely important and it is therefore brilliant to see that Kent police are allocating much needed time and funds to do just that. Being able to see you lead the session to a group of pupils has given me ideas and confidence to now use it myself." (Teacher questionnaire)

"Please continue your good work it is much needed to keep our children safe" (Parent questionnaire)

"Thank you - it is a thoughtful and purposeful resource" (Teacher Questionnaire)

"The presentation (by police) was very good in helping me understand the issue.....I believe this is something young people will really engage in" (Over 18 student questionnaire)

"Very good delivery of the training - Informative using case studies and background knowledge of the topic (sic)" (Over 18 student questionnaire)

\subsection{Future Application of Zak}

In a recent letter from Michael Gove to the head of every school in England, the education secretary sent a warning that all schools should be aware of signs of radicalisation, sexual exploitation and female genital mutilation (FGM). His advice urges head teachers not to think that 'it couldn't happen here' (BBC News 2014). Zak is a facilitative tool which addresses radicalisation and online grooming. It is easy to use and can be used in most environments and contexts and with young people of all ages.

When parents were asked, they saw Zak as an important tool for e-safety. Undergraduate students, when they had a session on it as part of a cross University initiative, immediately saw the relevance of Zak to schools; 'I think the simulation is very effective in highlighting an issue not often discussed, particularly in schools as well as being relevant to a range of social networking sites such as Twitter, Snapchat, Tumblr and Google+. This is particularly relevant given the evidence reviewed earlier that recruitment to radicalisation is carried out on the internet. The majority of students who returned their questionnaires felt they had good or 
excellent knowledge on the topic after the session.

Three primary schools were visited as a result of indications that the Zak concept had applicability to younger aged children. Although the purpose was to 'scope the idea' of a junior version of Zak, the enthusiastic feedback from all three primary school contributors was evident of their commitment to e-safety and the well-being of their pupils. Primary school feedback reported that a version of Zak would be useful,

"[...] to address safeguarding issues, problems with Instagrams, grooming online, selfharm and photos being published online." (Primary school)

The Staff in primary schools $(n=7)$ reported that mobile phones are used regularly by children in years 5 and 6 and even in year 4 - and children often have their own access to the internet via these devices. Staff expressed concern that these children are not protected as a result, and which was compounded if they have Xboxes in bedrooms and were online 'live'. Staff noted that in their experience some young children have an accurate awareness of differences between 'online' reality and 'real life'. Staff thought that the approach of Zak, as a game was beneficial because Zak seemed 'independent' and that this would work well for younger children as 'they aren't being told' as 'staff seem nagging so it is better as a peer group thing'.

The primary school staff who gave feedback to this evaluation said that younger children were in need of protection. They stated that some even have Twitter, they use Xbox Live and have a 'Facebook' profile and one reported that a child came into school with Netflix on a tablet. Staff felt that Zak had relevance for the younger child, after some adaptations and simplifications

"....you could look at race awareness through the character. It puts issues on the line, like friends requests. Locations are a potential danger. You have the chance to discuss ethics here too and raise awareness about grooming."

"You could talk about the dangers of chat rooms. It gets across the emotional bond formed by the manipulator, but I don't think I would concentrate on the radicalisation aspect."

When asked what they thought in principle of Zak as a junior version for primary school users ( $n=7$ ) thought Zak would be excellent, only qualified by the following comments

"A version for children, simpler to use, but in principle yes"

"This would be great adapted say a change in school age 10/11, especially as 10 is the age for criminal responsibility."

"It is really good that it is illustrated through a social media page. I think the discussion points are fantastic."

"You could pick up on that disclosure from a friend and get the children to explore that a good friend will tell, you shouldn't always keep a secret." 
"Zak hits on IT from a game view and this hasn't been done before has it?"

"You could do Zak moving from primary to secondary school. (Enthusiasm) You could revisit Zak as he grows, from early years because you get toddlers with mobile phones playing games. You could keep it relevant with the latest up to date changes in technology."

"The advantage is the whole group joining in approach because it is presented as a narrative. Our children will find this engaging and the captions make it more of a story. The two endings will appeal too, just needs to be for a lower age group a bit more step by step. Same principles just a slightly different focus and manner, but we do always need to raise awareness. I like the video at the end."

"You could challenge racism, grooming all sorts through this type of game".

"This is great for transitions" (i.e. primary to secondary schools)

\section{Conclusions}

Evidence clearly suggests that young people like to engage with simulations in the classroom (De Freitas 2011) and enjoy the interaction that this pedagogic approach brings. Online grooming and radicalisation are a part of contemporary society, the responsibility of which partly falls to schools to explore. It goes without saying that this is a potentially complex and difficult area to tackle either in groups or individually, by teachers who may not have any prior in depth knowledge or training on this topic. The Zak simulation indicates strongly that it is a successful learning tool on radicalisation when implemented collaboratively with support from experts and when teachers were trained by specialists to use it. Zak fits into the UK government strategies of PREVENT and CONTEST initiatives seeking to reduce extremism and violence. The need for Zak has been illustrated by the work of ICSR (2013, Kings College London) and the overall impression formed by this evaluation is that the simulation has been very well received by teachers who either used it in the classroom or who viewed it at a training or other event. Overall from this small pilot evaluation, Zak is a useful tool in the classroom to tackle issues of radicalisation and terrorism with young people. It also opens discussion on other complex and difficult topics, for example internet safety, geo location and grooming.

It is acknowledged that there are features in the simulation that could be improved to extend its use and give greater interaction and immersion for young people, for example the inclusion of other social media like 'Twitter', 'Instagram' and 'YouTube' Indeed the evaluation has provided valuable feedback for our new simulation 'Looking Out for Lottie' on Child Sexual Exploitation (CSE). However, in its current format Zak is seen as a flexible tool that can be used in small or larger group situations with young people in secondary school, parents and youth organisations. Such has been the success of 'Zak' that, following training, it is now available as a national resource for all schools.

With special thanks to Maria Le Hane for her work on the evaluation 


\section{Macrothink}

\section{References}

Al-Lami, M. (2009). Studies of Radicalisation: State of the Field Report. Politics and International Relations Working Paper, 11(7).

Bartlett, J., Birdwell, J., \& King, M. (2010), The Edge of Violence. A radical approach to extremism. Retrieved February 4, 2015, from https://www.publicsafety.gc.ca/lbrr/archives/ cn79051148-eng.pdf

BBC. (2014). How will government shut out the Trojan horse? Retrieved February 4, 2015, from http://www.bbc.co.uk/news/education-27024881

Bellotti, F., Berta, R., De Gloria, A., Panizza, G., Pellegrino, M., \& Primavera, L. (2011) Designing Serious Games for Cultural Heritage Purposes. In S. De Freitas, \& P. Maharg (Eds.), Digital Games and Learning (pp. 252-261). London, New York. Continuum International Publishing.

Borum, R. (2004). Psychology of Terrorism. Tampa: University of South Florida.

Brace, I. (2013) Questionnaire Design: How to Plan, Structure and Write Survey material for effective Market Research. Kogan Page Publishers

Brennan, C. (2011). You got pwned! The behaviour of young people online and the issues raised for teachers. Research in Secondary Teacher Education, 1(1), 16-20. Retrieved from http://hdl.handle.net/10552/1176

Davies, L., Harber, C., \& Yamashita, H. (2005). Global citizenship: The needs of teachers and learners. London: Department for International Development (DfID).

De Freitas, S., \& Maharg, P. (Eds.) (2011) Digital Games and Learning. London, New York. Continuum International Publishing.

Hacker, F. (1976). Crusader Criminals and Crazies: Terror and Terrorism in Our Time. New York: W.W.Norton.

Hoffman, B. (2006). Inside Terrorism. NY: Columbia University Press.

Laville, S. (2014), Social Media used to recruit new wave of British Jihadis in Syria. Retrieved from http://www.theguardian.com/world/2014/apr/15/social-media-recruit-britishjihadis-syria-twitter-facebook

Nulty, D. D. (2008) The adequacy of response rates to online and paper surveys: what can be done? Assessment \& Evaluation in Higher Education, 33(3), 301-314. http://dx.doi.org/10. 1080/02602930701293231

Ofsted. (2014) School Inspection Handbook. Manchester.

Ofsted. (2014). Inspecting e-safety in schools.

Oserweil, S., \& Kopfer, E. (2011). Are Games All Child's Play? In S. De Freitas, \& P. Maharg (Eds.), Digital Games and Learning (pp. 152-171). London, New York. Continuum 
International Publishing.

Razzaque, R. (2008). Human Being to a Human Bomb: Inside the Mind of a Terrorist. London: Icon Books.

See, B. H., \& Arthur, J. (2011). The potential role of schools and teachers in the character development of young people in England: perspectives from pupils and teachers. Evaluation \& Research in Education, 24(2), 143-157.Silke, A. (2008). Holy Warriors; Exploring the Psychological Processes of Jihadi Radicalisation. European Journal of Criminology, 5(1), 99-123. http:dx.doi.org/10.1177/ 1477370807084226

Speckhart, A. (2007). De-legitimising Terrorism: Creative Engagement and Understanding of the Psycho-Social and Political Processes Involved in Ideological Support for Terrorism. Connections. Winter, 1.

Thomson, R., \& Holland, J. (2002). Young people, social change and the negotiation of moral authority. Children \& Society, 16(2), 103-115. http:dx.doi.org/10.1002/chi.703

\section{Appendix}

Table 2. Some of the 'posts' on 'Zak' and some of the suggested teaching and learning points for use in the classroom

\begin{tabular}{|c|c|c|c|c|c|}
\hline POST & YEARS 9-11 & YEARS 12+ & $\begin{array}{l}\text { COMMENTS } \\
\text { YEARS 9-11 }\end{array}$ & $\begin{array}{l}\text { COMMENTS YEARS } \\
12+\end{array}$ & $\begin{array}{l}\text { FURTHER } \\
\text { READING }\end{array}$ \\
\hline 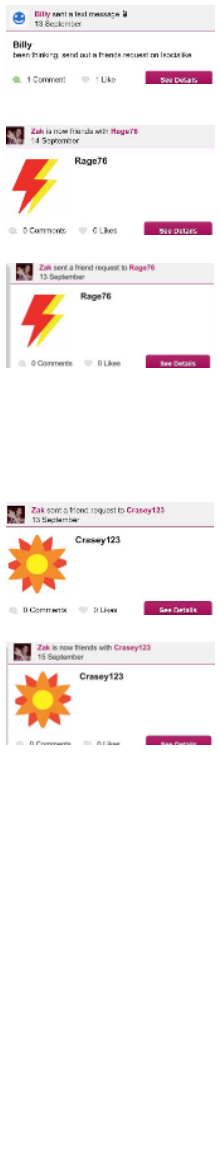 & $\begin{array}{l}\text { How do you } \\
\text { manage your } \\
\text { profile on social } \\
\text { media sites? } \\
\text { How can people } \\
\text { gain access to } \\
\text { your social } \\
\text { media pages- } \\
\text { what are you } \\
\text { allowing them to } \\
\text { see about you } \\
\text { and your life }\end{array}$ & $\begin{array}{l}\text { Zak is vulnerable- } \\
\text { can you analyse } \\
\text { the dangers of } \\
\text { accepting } \\
\text { 'strangers' as } \\
\text { friends. When does } \\
\text { a stranger become } \\
\text { a friend? What } \\
\text { characteristics are } \\
\text { you looking for in } \\
\text { a friend? } \\
\text { Explore privacy } \\
\text { setting on these } \\
\text { sites. }\end{array}$ & $\begin{array}{l}\text { There is a great deal } \\
\text { of information on } \\
\text { social networking } \\
\text { sites that can help } \\
\text { individuals create a } \\
\text { profile of victims- } \\
\text { allowing them to } \\
\text { understand your } \\
\text { interest, like and } \\
\text { dislike which will } \\
\text { help them be } \\
\text { plausible in create an } \\
\text { emotional bond. }\end{array}$ & & $\begin{array}{l}\text { Who can search for } \\
\text { you - this means } \\
\text { that when people } \\
\text { search your name on } \\
\text { a site, your profile } \\
\text { does not come up. } \\
\text { Who sees what - } \\
\text { this means that you } \\
\text { can control the } \\
\text { information you } \\
\text { share, like your } \\
\text { photos or 'wall' } \\
\text { posts. You can } \\
\text { usually restrict this } \\
\text { to friends only, } \\
\text { friends of friends, } \\
\text { certain groups of } \\
\text { friends, or everyone. } \\
\text { We would } \\
\text { recommend that for } \\
\text { young people it is } \\
\text { restricted to friends }\end{array}$ \\
\hline
\end{tabular}




\begin{tabular}{|c|c|c|c|c|c|}
\hline & & & & & only. \\
\hline 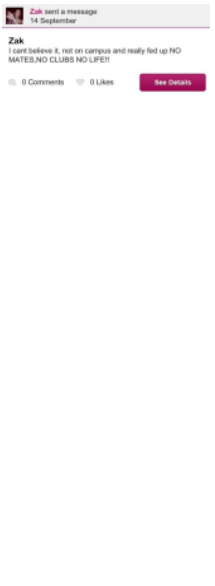 & $\begin{array}{l}\text { How do you } \\
\text { think Zak is } \\
\text { feeling at this } \\
\text { moment in time? }\end{array}$ & $\begin{array}{l}\text { How does this } \\
\text { make Zak more } \\
\text { vulnerable? How } \\
\text { might you negate } \\
\text { these } \\
\text { vulnerabilities - } \\
\text { for example what } \\
\text { types of support } \\
\text { could be built in? }\end{array}$ & $\begin{array}{l}\text { Highlight the } \\
\text { vulnerabilities and } \\
\text { isolation of Zak }\end{array}$ & $\begin{array}{l}\text { Understanding that the } \\
\text { radicalisation process is } \\
\text { similar to any other } \\
\text { grooming process but } \\
\text { also that it works with } \\
\text { the same thread that } \\
\text { allows an individual to } \\
\text { be safeguarded.(trust, } \\
\text { emotional bond, the } \\
\text { feeling that the } \\
\text { individual is understood) }\end{array}$ & $\begin{array}{l}\text { See research- } \\
\text { Need for identity, } \\
\text { meaning, belonging: }\end{array}$ \\
\hline (1) & $\begin{array}{l}\text { What does K.I.A } \\
\text { mean? } \\
\text { Why is this post } \\
\text { from Crasey } \\
\text { worrying? Is } \\
\text { Zak's reply } \\
\text { appropriate? }\end{array}$ & $\begin{array}{l}\text { Analyse Crasey's } \\
\text { strategies for } \\
\text { grooming Zak. }\end{array}$ & $\begin{array}{l}\text { K.I.A- killed in } \\
\text { action } \\
\text { There is little } \\
\text { emotion linked to the } \\
\text { reply from Zak, this } \\
\text { hints at the fact the } \\
\text { Zak is now starting to } \\
\text { desensitise himself } \\
\text { from death. }\end{array}$ & $\begin{array}{l}\text { Crasey is creating an } \\
\text { emotional bond with } \\
\text { Zak, giving him the } \\
\text { sense that he can relate to } \\
\text { Zak in a way that others } \\
\text { cannot. As highlighted } \\
\text { before once this is place } \\
\text { this leaves Zak open to } \\
\text { manipulation. }\end{array}$ & $\begin{array}{l}\text { See research- } \\
\text { Need for identity, } \\
\text { meaning, belonging: }\end{array}$ \\
\hline
\end{tabular}

\section{Copyright Disclaimer}

Copyright reserved by the author(s).

This article is an open-access article distributed under the terms and conditions of the Creative Commons Attribution license (http://creativecommons.org/licenses/by/3.0/). 